\title{
Mechanical stretch up-regulates the B-type natriuretic peptide system in human cardiac fibroblasts: a possible defense against transforming growth factor- $\beta$ mediated fibrosis
}

Chris J Watson ${ }^{1 \dagger}$, Dermot Phelan ${ }^{1 \dagger}$, Maojia Xu ${ }^{1}$, Patrick Collier ${ }^{1}$, Roisin Neary ${ }^{1}$, Albert Smolenski ${ }^{1}$, Mark Ledwidge ${ }^{2}$, Kenneth McDonald ${ }^{2}$ and John Baugh ${ }^{1^{*}}$

\begin{abstract}
Background: Mechanical overload of the heart is associated with excessive deposition of extracellular matrix proteins and the development of cardiac fibrosis. This can result in reduced ventricular compliance, diastolic dysfunction, and heart failure. Extracellular matrix synthesis is regulated primarily by cardiac fibroblasts, more specifically, the active myofibroblast. The influence of mechanical stretch on human cardiac fibroblasts' response to pro-fibrotic stimuli, such as transforming growth factor beta (TGF $\beta$ ), is unknown as is the impact of stretch on Btype natriuretic peptide (BNP) and natriuretic peptide receptor A (NPRA) expression. BNP, acting via NPRA, has been shown to play a role in modulation of cardiac fibrosis.

Methods and results: The effect of cyclical mechanical stretch on TGF $\beta$ induction of myofibroblast differentiation in primary human cardiac fibroblasts and whether differences in response to stretch were associated with changes in the natriuretic peptide system were investigated. Cyclical mechanical stretch attenuated the effectiveness of TGF $\beta$ in inducing myofibroblast differentiation. This finding was associated with a novel observation that mechanical stretch can increase BNP and NPRA expression in human cardiac fibroblasts, which could have important implications in modulating myocardial fibrosis. Exogenous BNP treatment further reduced the potency of TGF $\beta$ on mechanically stretched fibroblasts.
\end{abstract}

Conclusion: We postulate that stretch induced up-regulation of the natriuretic peptide system may contribute to the observed reduction in myofibroblast differentiation.

Keywords: Mechanical stretch, BNP, Natriuretic peptide receptor A, Transforming growth factor beta, Myofibroblast, Alpha smooth muscle actin

\section{Background}

Hypertensive heart disease describes a phase of remodeling which occurs in the myocardium when exposed to sustained elevation in arterial blood pressure or hypertrophic substances associated with the hypertension syndrome. The two most notable features of hypertensive heart disease are myocyte hypertrophy and reactive

\footnotetext{
* Correspondence: john.baugh@ucd.ie

${ }^{\dagger}$ Equal contributors

'School of Medicine \& Medical Science, The Conway Institute of Biomolecular and Biomedical Research, University College Dublin, Dublin, Ireland

Full list of author information is available at the end of the article
}

fibrosis. The relationship between reactive fibrosis and hypertension is well described [1-3].

In physiological terms, the effect of this fibrosis is a reduction in compliance of the myocardium and diastolic dysfunction. This premise is based on two principles. Firstly, the addition of fibrillar collagen to normal tissue results in reduced compliance of that tissue, and secondly, regression of such fibrosis improves compliance and reduces cardiac stiffness [4-8]. The synthesis and degradation of fibrillar collagen is regulated by the myocardial fibroblast. Fibroblast differentiation to the more active myofibroblast form is a hallmark of cardiac 
fibrosis, and is associated with increased collagen production, enhanced proliferative and migratory potential, and is associated with increased expression of alphasmooth muscle actin (ASMA) [9]. Although myofibroblast differentiation is an essential process required for normal wound healing, prolonged injury or perhaps loss of regulation can result in pathological fibrosis.

Modulation of pro-fibrotic signals within the myocardium is necessary to regulate normal wound healing processes. One possible regulator may be B-type natriuretic peptide (BNP). BNP is an endogenous hormone which is known to be secreted by cardiac myocytes in response to myocardial stretch and overload and is an important regulator of blood volume homeostasis through its diuretic, natriuretic, and vasodilating actions and by inhibiting renin and aldosterone [10,11]. More recent data suggest that natriuretic peptides also appear to play a major role in modulation of both cardiac and renal fibrosis [12-14].

The aim of this study was to investigate the combined effects of mechanical stretch and the pro-fibrotic cytokine transforming growth factor beta (TGF $\beta$ ) on myofibroblast differentiation, and the impact of BNP in this process.

\section{Results}

The impact of mechanical stretch on human primary cardiac fibroblast cells response to recombinant TGF $\beta$ was investigated. These experiments were carried out on flexible six well culture plates coated with $2 \mu \mathrm{g} / \mathrm{cm}^{2}$ human fibronectin, as described in the Methods section. Cells at a confluency of approximately 70\% were exposed to cyclic equibiaxial Heart Simulation strain (1 Hz, maximum elongation 10\%) for $72 \mathrm{~h}$. Control plates were exposed to the same conditions without being stretched. These experiments were carried out either in the presence or absence of $10 \mathrm{ng} / \mathrm{mL}$ recombinant TGF $\beta$.

\section{TGF $\beta$-induced ASMA and collagen 1 is reduced on mechanically stretched cardiac fibroblast cells}

The combined effects of mechanical stretch and TGF $\beta$ treatment on human primary cardiac fibroblast expression of the differentiation marker ASMA and the profibrotic markers collagen 1 and 3 were investigated. Quantitative real-time PCR analysis revealed that TGF $\beta$ induction of ASMA gene expression was significantly reduced on stretched cells. TGF $\beta$ treatment for $72 \mathrm{~h}$ on non-stretched cells up-regulated ASMA by over 15-fold, whereas TGF $\beta$ stimulated ASMA expression was only two-fold in stretched cells, $P<0.001$ (Figure 1A). A similar response was detected for collagen 1, where TGF $\beta$ induction of collagen 1 gene expression was reduced from approximately four-fold to two-fold when cells were mechanically stretched compared to nonstretched cells, $P<0.001$ (Figure $1 \mathrm{~A}$ ). Interestingly, unlike ASMA and collagen1, TGF $\beta$ induction of collagen 3 expression was significantly enhanced when cells were mechanically stretched, $P<0.05$. Due to the magnitude of the suppressive effects of stretch on TGF $\beta$ upregulation of ASMA, this observation was verified at the protein level by Western blotting, where TGF $\beta$ induced ASMA was significantly diminished in stretched cells, $P<0.001$ (Figure 1B).

\section{Diminished responses to exogenous TGF $\beta$ on mechanially stretched cardiac fibroblast cells are not due to decreased basal expression levels of TGF $\beta$}

The impact of cyclical mechanical stretch on basal and TGF $\beta$ stimulated expression of TGF $\beta$, and its receptor subtypes 1 and 2 (TGF $\beta$-R1; TGF $\beta-R 2$ ) were investigated. Human cardiac fibroblast cells underwent mechanical stretch for $72 \mathrm{~h}$ in the presence or absence of $10 \mathrm{ng} / \mathrm{mL}$ TGF $\beta$. Quantitative gene expression analysis revealed that mechanical stretch did not alter the levels of TGF $\beta$ receptors (Figure 2A). However, mechanical stretch did impact the basal expression levels of TGF $\beta$. A significant 2.5-fold increase in gene expression was observed $(P<0.05)$ (Figure 2A). Further evidence that the diminished response to exogenous TGF $\beta$ on mechanically stretched cells was not due to reduced basal expression of TGF $\beta$, or its receptors, is shown in Figure 2B. A reduction in Smad2 phosphorylation was not observed under stretched conditions. Of note, treatment with TGF $\beta$ in stretched cells resulted in a 10-fold increase in basal expression of TGF $\beta$ gene expression $(P<0.01)$, Figure $2 C$, but had no impact on expression of its receptors (data not shown). The impact of mechanical stretch and recombinant TGF $\beta$ treatment on HCF production of TGF $\beta$ protein production was investigated. Both total and active TGF $\beta 1$ was quantified in the supernatant of HCF using ELISA based methods (Figure 2D). The relatively large increase in TGF $\beta$ mRNA expression in cells exposed to mechanical stretch and recombinant TGF $\beta$ stimulation was not reflected at the protein level. The highest concentration of secreted TGF $\beta$ protein (both latent and active) was in un-stretched cardiac fibroblast cells stimulated with recombinant TGF $\beta$ treatment for $72 \mathrm{~h}$. The impact of stretch alone did not have a significant impact on TGF $\beta$ secretion (although a downward trend was apparent). However, the ability of recombinant TGF $\beta$ to stimulate endogenous TGF $\beta$ production was reduced when the cells were mechanically stretched. Interestingly however, it is important to note that the detectable levels of secreted TGF $\beta$ were $<1 \mathrm{pg} / \mathrm{mL}$, thus the physiological relevance of these small changes within the experimental cell culture environment is unknown, especially under conditions of recombinant TGF $\beta$ treatment were cells are exposed to $10,000 \mathrm{x}$ this concentration.

Collectively, these data suggest that the observed reduction in TGF $\beta$-mediated myofibroblast differentiation 


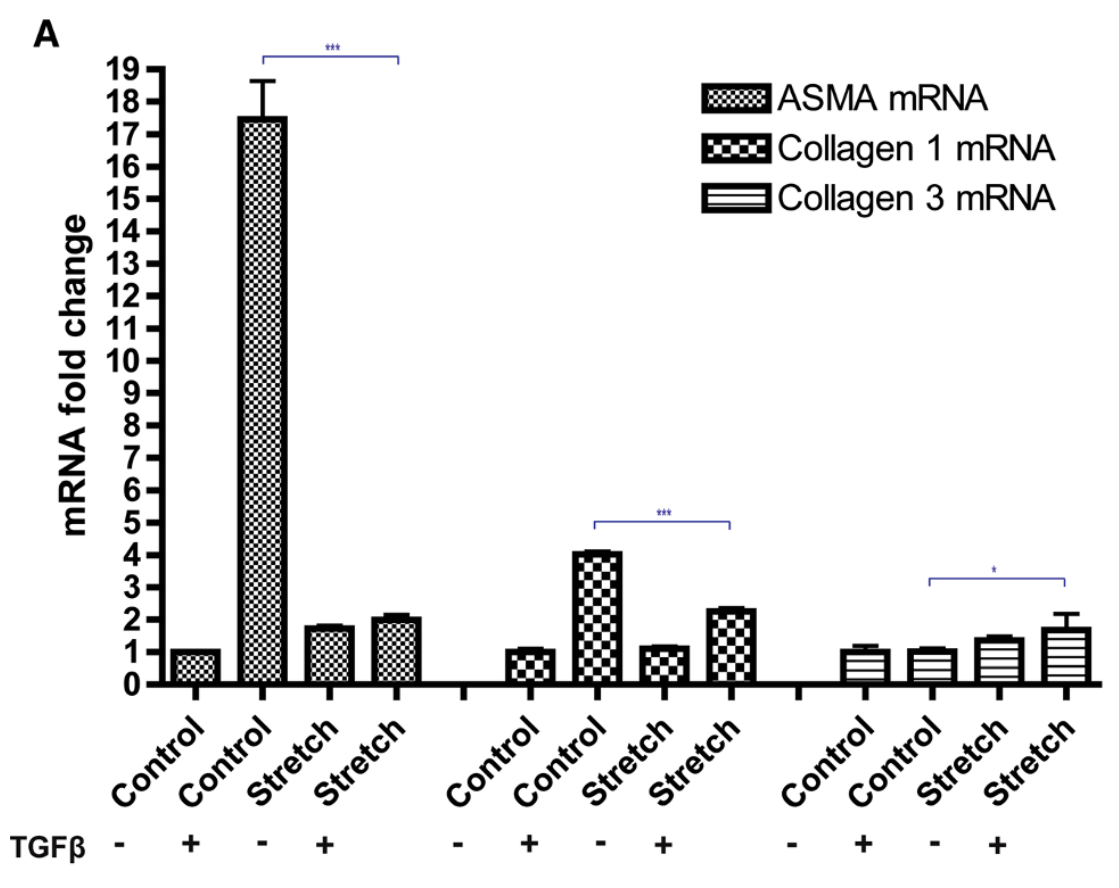

B

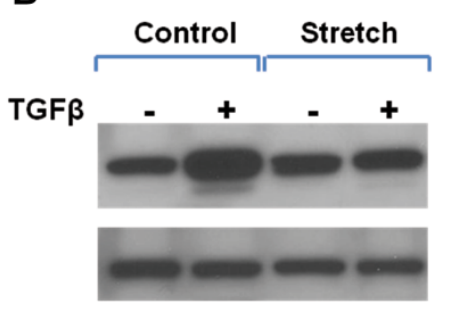

ASMA

Tubulin

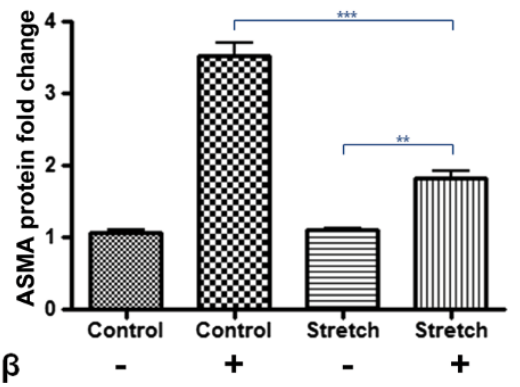

Figure 1 Mechanical stretch reduces TGF $\beta$ induction of alpha-smooth muscle actin (ASMA) and collagen 1 expression in human cardiac fibroblasts. Human primary cardiac fibroblasts underwent either biaxial mechanical stretch for $72 \mathrm{~h}$ or were left un-stretched (control), in the presence of $10 \mathrm{ng} / \mathrm{mL}$ transforming growth factor beta (TGF $\beta$ ). Alterations in ASMA, collagen 1, and collagen 3 gene expression were examined using quantitative real-time PCR analysis (A). Western blotting was used to quantify changes in ASMA protein expression (B). Antitubulin was utilized as a loading control for western blotting, allowing for semi-quantitative densitometry analysis. Bar graphs represent mean fold change \pm SD. ${ }^{*} P<0.05,{ }^{* *} P<0.01,{ }^{* * *} P<0.001$

on mechanically stretched cells does not occur through a reduction in gene expression levels of TGF $\beta$ or receptor subtype 1 or 2 . Concentration differences in secreted TGF $\beta$ are minimal and are unlikely to be responsible for the observed reduction of TGF $\beta$ induction of ASMA in stretched cells highlighted in Figure 1. This is further supported by intact Smad2 and ERK phosphorylation in response to short time point stimulation with TGF $\beta$ (15 and $45 \mathrm{~min}$ ) post $72 \mathrm{~h}$ mechanical stretch.

\section{Mechanical stretch up-regulates both BNP and its} receptor NPRA in primary human cardiac fibroblast cells Cardiac fibroblast cells exposed to mechanical stretch for $72 \mathrm{~h}$ exhibited a significant increase in gene expression of BNP and its receptor natriuretic peptide receptor
A (NPRA). BNP and NPRA were significantly upregulated by over 25 -fold $(P<0.001)$ and almost fourfold $(P<0.01)$, respectively (Figure $3 \mathrm{~A})$. TGF $\beta$ treatment in non-stretched conditions did not significantly impact BNP or NPRA gene expression levels. Interestingly, TGF $\beta$ treatment in the presence of stretch further increased the expression level of BNP. A trend towards a negative impact of TGF $\beta$ treatment on NPRA gene expression was observed. NPRA protein expression was apparent in both non-stretched and stretched fibroblast cells by immunofluorescence microscopy. However, the intensity of positive immuno-staining was greater in cells that underwent mechanical stretch (Figure 3B). Quantitative evidence of increased NPRA protein expression in stretched cardiac fibroblasts was observed using western 


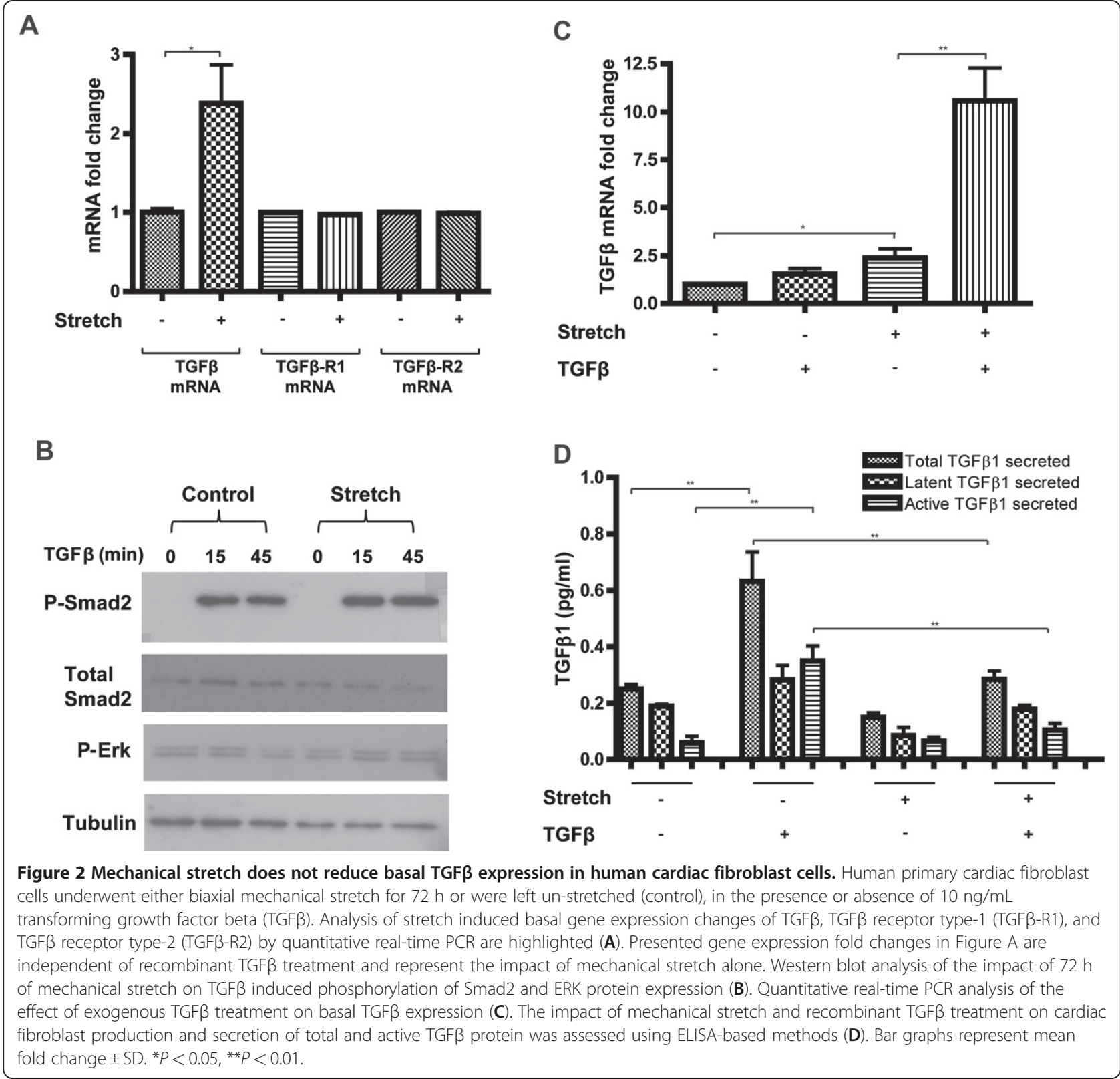

blotting. NPRA protein expression was up-regulated more than two-fold following $72 \mathrm{~h}$ of mechanical stretching $(P<0.01)$ (Figure $3 C)$. Cell lysates derived from transient over-expression of NPRA served as a positive control.

Exogenous BNP further reduces the pro-fibrotic effects of TGF $\beta$ on stretched primary human cardiac fibroblast cells The reduced potency of TGF $\beta$ to induce myofibroblast differentiation on stretched cardiac fibroblasts was further investigated in the context of stretch induced BNP and NPRA expression. The impact of recombinant BNP treatment in combination with TGF $\beta$ on stretched cells was explored. It was found that the anti-fibrotic effects of exogenous BNP, as measured by ASMA protein repression, were only apparent when cardiac fibroblasts were mechanically stretched for $72 \mathrm{~h}$ (Figure 4).

\section{Discussion}

TGF $\beta$ is a powerful mediator of adverse cardiac remodeling and fibrosis primarily via Smad-dependent induction of collagen expression as well as differentiation of fibroblasts to the myofibroblast phenotype which exhibits increased secretory, migratory, and proliferative properties and express the contractile protein ASMA [15-18]. The current study presents a novel observation that the pro-fibrotic effects of TGF $\beta$ are reduced on mechanically stretched human primary cardiac fibroblasts. 


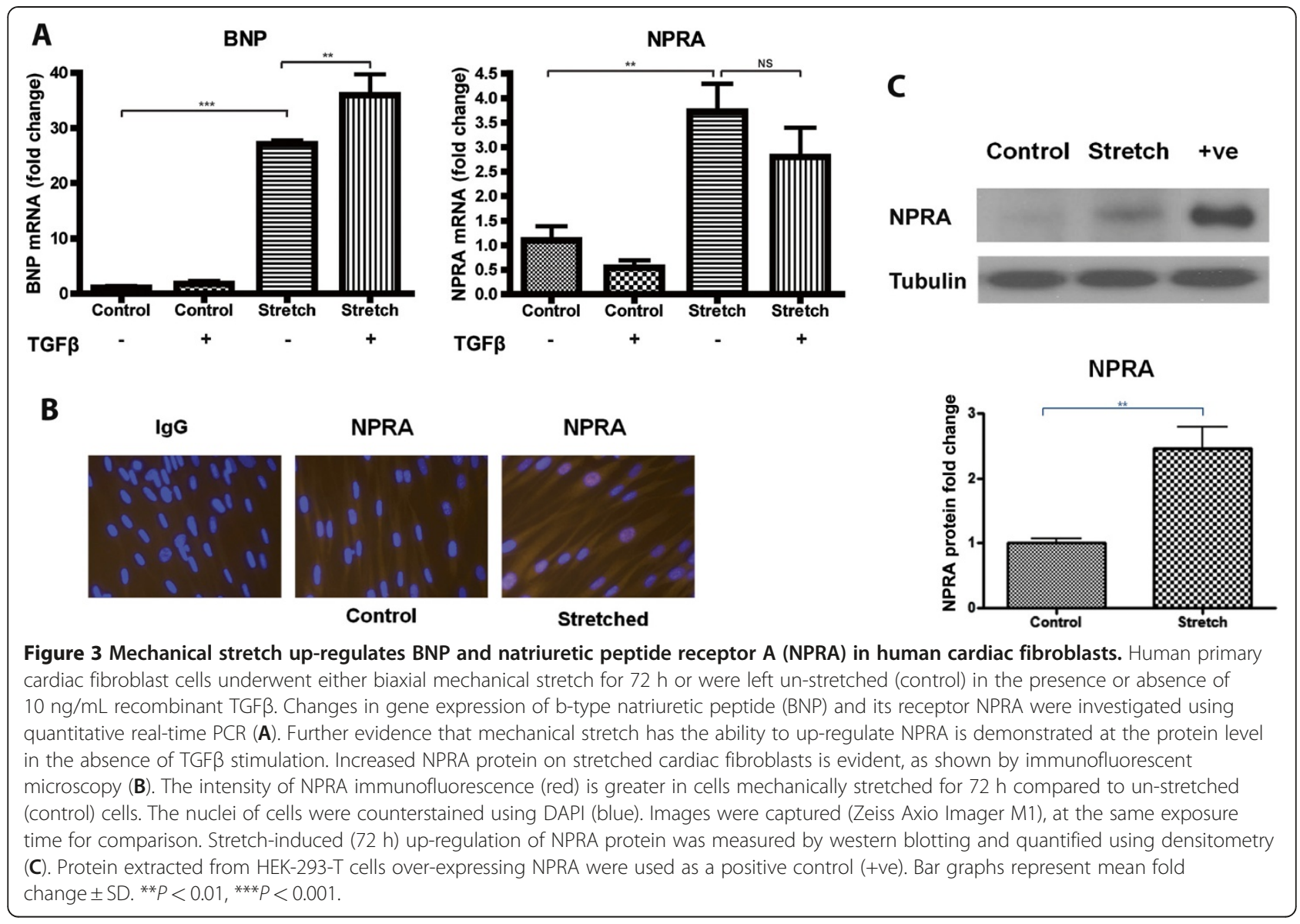

In addition to this, we also document for the first time that mechanical stretch can up-regulate BNP and NPRA expression in human primary cardiac fibroblast cells, which could have important implications in modulating myocardial fibrosis. This point is emphasized by the observed increased anti-fibrotic effect of exogenous BNP treatment on stretched fibroblasts.

Within a normal or exaggerated wound healing environment additional stimuli are present along with profibrotic factors such as TGF $\beta$ which may impact cellular activities. These may include the impact of tissue ischemia, circulating neuro-hormonal factors, or mechanical stretch on cellular behavior. A pressure or volume overloaded heart may exert increased mechanical strain at a cellular level. In combination with a pro-fibrotic environment, these additional heart stresses may impact disease progression, such as cardiac fibrosis and tissue remodeling.

One component of this study was to determine whether the impact of TGF $\beta$ on primary human cardiac fibroblasts was different on mechanically stretched cells compared with static cells. Surprisingly, we found that TGF $\beta$ induced ASMA expression was reduced when cells underwent cyclical stretch compared to static cells.
This was also apparent for collagen 1 gene expression, but not collagen 3. Based on previous work using various cardiovascular cell types from a range of animal species, we anticipated that the combination of mechanical stretch and TGF $\beta$ treatment would have increased ASMA and collagen 1 expression compared with TGF $\beta$ treated static cells resulting in an enhanced pro-fibrotic effect [19-21]. Interestingly, our finding that mechanical stretch reduces myofibroblast differentiation has recently been supported by similar observations in primary lung fibroblasts [22]. Here, Blaauboer et al. investigated the impact of sinusoidal stretch on lung fibroblast response to TGF $\beta$. The authors suggest that their observed reduction in the ability of exogenous TGF $\beta$ to induce ASMA was due to a stretch mediated down-regulation of basal TGF $\beta$ gene expression. However, we do not observe this in our system with primary human cardiac fibroblast cells. In fact, we observe an increase in basal levels of TGF $\beta$ gene expression. However, when examining the protein levels of TGF $\beta$ produced and released by the HCF, it was observed that the ability of recombinant TGF $\beta$ to stimulate endogenous TGF $\beta$ production was reduced when the cells were mechanically stretched. It is important to note that the detectable levels of secreted 


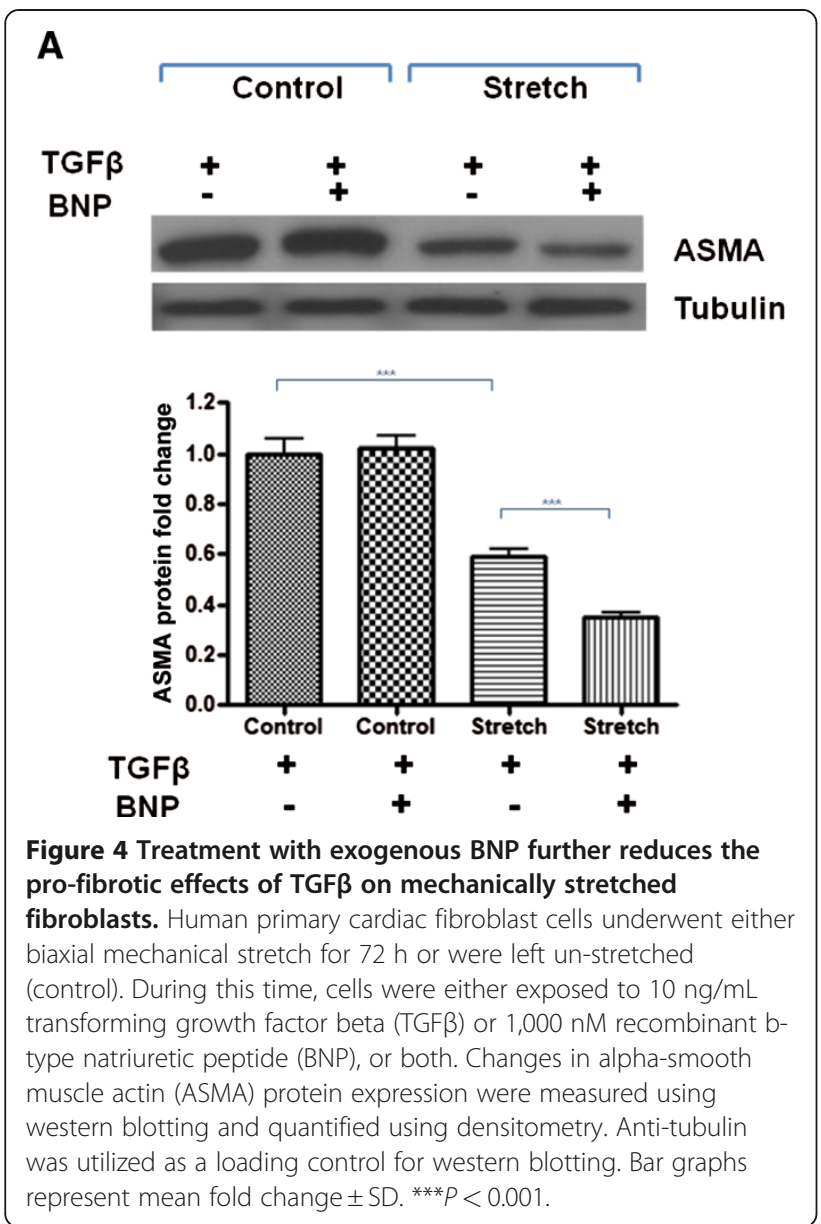

TGF $\beta$ were $<1 \mathrm{pg} / \mathrm{mL}$, which likely rules out a paracrine effect of TGF $\beta$ released from the HCF being the driver of the reduced myofibroblast differentiation in the presence of stretch and recombinant TGF $\beta$. Within an in vivo setting the main source of TGF $\beta$ driving myofibroblast differentiation in the myocardium is from other cell types, including the tissue invading inflammatory cell component and cardiomyocytes [23-26].

As we do not detect reduced levels of TGF $\beta$, or its receptor subtypes TGF $\beta$-R1 and TGF $\beta$-R2 gene expression, minimally detectable levels of secreted active or total TGF $\beta$ within the cells supernatant $(<1 \mathrm{pg} / \mathrm{mL})$ or reduced Smad 2 phosphorylation, we believe that stretch-mediated inhibition of TGF $\beta$-induced cardiac fibroblast differentiation occurs independently of TGF $\beta$ receptor signaling or downstream of Smad 2. One alternative mechanism may involve ERK signaling as it has recently been reported that TGF $\beta$ mediated ERK phosphorylation under conditions of cyclical stretching can be impaired [27]. However, we do not observe reduced ERK phosphorylation when comparing the impact of short time point (15 and $45 \mathrm{~min}$ ) TGF $\beta$ stimulation in cells that have been stretched for $72 \mathrm{~h}$ vs. non-stretched cells. Investigating the impact of chronic stimulation with TGF $\beta$ on ERK phosphorylation under mechanical stretch conditions would be of interest.

In parallel to stretch-induced attenuation of TGF $\beta$ response, we report an important novel observation that mechanical stretch can up-regulate the expression of both BNP and its receptor NPRA in human cardiac fibroblast cells. In addition, TGF $\beta$ stimulation in the presence of mechanical stretch can further enhance the observed BNP up-regulation. BNP has been reported to be synthesized in both animal and human cardiac fibroblasts [28-30], however the impact of stretch on its expression in these cells has not been noted to date. In addition, the impact of mechanical stretch on fibroblast expression of NPRA has not been explored. Although up-regulation of BNP expression following mechanical stretch of cardiomyocytes is well-documented, it is only more recently that mechanisms of this are being teased out. For example, a publication by Koivisto and colleagues highlight an important observation that ERK mediated activation of the muscle-CAT (MCAT) promoter element within the BNP gene contributes to stretch induced BNP up-regulation in cardiomyocytes [31]. Determining whether similar mechanisms occur in myofibroblasts would be important, however, MCAT activation within this cell type may be mediated by a different means [32].

These two observations that mechanical stretch can up-regulate BNP and NPRA in cardiac fibroblasts have important implications on our understanding of fibroblast biology in the context of the fibro-inhibitory effects of BNP [13,28]. Given that NPRA has recently been shown to play a protective role in an animal model of renal fibrosis [14] the relevance of stretch-regulated NPRA expression may extend to other organ systems. Although we do not show that endogenous production of BNP and enhanced NPRA expression directly accounts for attenuation of the TGF $\beta$ response, we do provide evidence that the anti-fibrotic effects of BNP are enhanced in stretched cells in line with the increase in NPRA expression. Western blot analysis of ASMA revealed that the observed inhibition of TGF $\beta$-induced ASMA on stretched cardiac fibroblasts was further enhanced in the presence of exogenous recombinant BNP. Although exogenous BNP inhibits ASMA mRNA expression in static cardiac fibroblasts (data not shown) we demonstrate here that it has little effect on ASMA protein expression. Presumably this is due to the relatively low expression of NPRA on un-stretched cardiac fibroblasts. The impact of exogenous BNP on cardiac fibroblast function is highly relevant, given that the majority of BNP encountered by cardiac fibroblasts is likely to originate from the cardiomyocytes. However, fibroblast production of BNP may have an autocrine/ 
paracrine effect and provide regulation at a local level. This could be particularly important in scar tissue, were fibroblast cells are isolated from neighboring myocytes within a sea of collagen.

Further work is required to delineate the precise mechanisms behind our findings, including the investigation of additional experimental time points, concentration of agonists used, and degree of mechanical stretch applied. Under normal physiological conditions, cardiac fibroblasts are exposed to cyclical mechanical stretch with each heart beat, at a frequency of approximately $1 \mathrm{~Hz}$. Given the different cellular responses observed in this study when cells are exposed to cyclical mechanical stretch compared with static cells, additional studies expanding these observations in an enhanced pathological setting are warranted. In particular, it may be worth assessing the impact of increasing the degree of mechanical strain beyond $10 \%$ elongation or varying the level of TGF $\beta$ stimulation on the findings reported herein. Application of continuous cyclical mechanical stretch for durations beyond $72 \mathrm{~h}$ may provide a more accurate representation of hypertensive heart disease which is a chronic condition that exposes the myocardium to long periods of strain.

On this note, it must be highlighted that this study utilized one primary cell line from a healthy donor, and therefore to investigate these findings further one would need to take a more comprehensive approach using multiple primary cells lines from various donors spanning the age and cardiovascular health spectrum. It is possible that cardiac fibroblasts derived from a disease myocardium may behave differently, for example, the pathway controlling stretch up-regulation of BNP or NPRA may not be functional in diseased fibroblasts.

An additional benefit of using multiple primary cell lines from various donors would be to determine whether our observed findings are applicable to an array of phenotypically diverse fibroblast cells across the spectrum of myofibroblast differentiation. Extensive work carried out by Gabbiani and colleagues has highlighted an important intermediate phenotype between a fibroblast and a myofibroblast, termed the protomyofibroblast $[21,33]$. The evolution of a fibroblast to a proto-myofibroblast is signified by the presence of beta and gamma actin stress fibers, with the development of cytoplasmic ASMA fibers only appearing in the fully differentiated myofibroblast [21,33]. The primary cardiac fibroblasts used in this study exhibited basal mRNA and protein expression of the contractile protein ASMA, however, ASMA stress fibers were not detected in control cells by immunocytochemistry (data not shown). It is therefore likely that these primary cells are on the continuum between a phenotypic fibroblast and a myofibroblast, and therefore may be more appropriately referred to as 'proto-myofibroblasts'. With this in mind, the observed responses to mechanical stimuli herein may only be relevant to proto-myofibroblasts. This could also account for some of the conflicting findings with current literature as previously mentioned [19-21].

Cellular interpretation of a mechanical stimulus is likely to be influenced by the surrounding extracellular matrix, thus investigating the importance of integrin signaling during stretched cardiac fibroblast's response to TGF $\beta$ and BNP should be considered [29,34,35]. For example, it is possible that the cellular responses we observed may be specific to cardiac fibroblasts interacting with extracellular matrix proteins containing RGD (Arg-Gly-Asp) domains, such as fibronectin and collagen IV $[29,36]$. Interestingly, NPRA has been demonstrated to interact with RGD-binding integrin receptors thereby enhancing BNP activation of cGMP in human cardiac fibroblasts $[29,36]$.

\section{Conclusion}

In summary, our data expand on the complex relationship between mechanical strain and cell/matrix interactions and human cardiac fibroblast physiology. We demonstrate that cell deformation via cyclical biaxial strain attenuates the effectiveness of TGF $\beta$ in inducing myofibroblast differentiation while simultaneously inducing BNP and NPRA production in human cardiac fibroblast cells. We confirm the inhibitory properties of BNP on TGF $\beta$ regulation of the myofibroblast differentiation marker ASMA and show that exogenous BNP treatment of stretched fibroblasts further reduces the potency of TGF $\beta$. We postulate that the stretch-induced upregulation of the natriuretic peptide system could account for these findings. These findings may describe a novel protective negative feedback mechanism for cardiac fibroblasts exposed to multiple pro-fibrotic stimuli and would encourage future work to directly link this observation, possibly through the use of siRNA experiments or NPRA receptor antagonists.

\section{Methods}

\section{Cell culture}

Primary human cardiac fibroblast cells from the adult ventricle (HCF) were purchased from ScienCell Research Laboratories. Primary cells were derived from a single female donor aged 20 years. Until required for experiments, cells were cultured and maintained in Dulbecco's modified eagles medium (DMEM) (Gibco), supplemented with $10 \%$ fetal bovine serum (Gibco) and penicillinstreptomycin antibiotics (Gibco) in a $5 \% \mathrm{CO}_{2}$ humidified incubator kept at $37{ }^{\circ} \mathrm{C}$. All experiments involving cardiac fibroblasts were carried out under serum-free conditions. 


\section{Transfection}

HEK-293-T cells were used to generate a positive control for natriuretic peptide receptor A (NPRA; also known as guanylyl cyclase A, GCA) expression. Cells were purchased from American Type Culture Collection (ATCC) and were cultured in DMEM supplemented in the same manner as for HCF cells. HEK-293-T cells were transiently transfected in six well plates for $48 \mathrm{~h}$ with $1 \mu \mathrm{g} /$ well of a pcDNA3_NPRA expression construct (kind gift from Dr Michaela Kuhn, University of Wurzburg, Germany) or empty vector using FuGENE (Roche) as recommended by the manufacturer's instructions.

\section{Treatments}

Where indicated, HCF cells were treated with $10 \mathrm{ng} / \mathrm{mL}$ human recombinant TGF $\beta 1$ (R\&D Systems) for $72 \mathrm{~h}$. For analysis of Smad phosphorylation, cells were treated with TGF $\beta 1$ for 15 or $45 \mathrm{~min}$. Human recombinant BNP was purchased from American Peptide Company Inc. HCF cells were treated with recombinant BNP at a concentration of $1000 \mathrm{nM}$ for $72 \mathrm{~h}$. BNP was added to the medium three times a day as previously described [13].

\section{Mechanical stretch}

All mechanical stretch experiments were carried out on BioFlex six well culture plates (Dunn Labortechnik $\mathrm{GmbH})$ coated with $2 \mu \mathrm{g} / \mathrm{cm}^{2}$ human fibronectin (Sigma). Cells were seeded and grown to a confluency of approximately $70 \%$ on the fibronectin-coated BioFlex culture plates prior to transfer onto the loading station of the FX-4000 T mechanical stretch machine (Flexcell International Corporation), and exposed to cyclic equibiaxial Heart Simulation strain $(1 \mathrm{~Hz}$, maximum elongation $10 \%$ ) for $72 \mathrm{~h}$. Control plates were exposed to the same conditions without being stretched.

\section{Quantitative real-time PCR (QPCR)}

RNA isolation from cells was achieved using NucleoSpin RNA II Kit (Macherey-Nagel). First strand cDNA synthesis was carried out using SuperScript II RT (Invitrogen). QPCR primers were designed so that one of each primer pair was exon/exon boundary spanning to ensure only mature mRNA was amplified. The sequences of the gene-specific primers used are as follows; BNP, 5'-ACCG CAAAATGGTCCTCTAC-3' (forward), 5' - CGCCTCA GCACTTTGCAG-3' (reverse); NPR1, 5'-CGCAAAGG CCGAGTTATCTA-3' (forward), 5'-AACGTAGTCCTC CCCACACA-3' (reverse); ASMA, 5' -CGTTACTACTG CTGAGCGTGA-3' (forward), 5'-AACGTTCATTTCC GATGGTG-3' (reverse); collagen $1 \alpha 1$ (COL1A1), 5'-G AACGCGTGTCATCCCTTGT-3' (forward), 5' -GAACG AGGTAGTCTTTCAGCAACA-3' (reverse); collagen 3 a1 (COL3A1), 5' - AACACGCAAGGCTGTGAGACT3' (forward), 5' - GAACGAGGTAGTCTTTCAGCAAC
A-3' (reverse); TGF $\beta$, 5' -CGACTCGCCAGAGTGGTT A-3' (forward), 5'-GAACCCGTTGATGTCCACTT-3' (reverse); TGF $\beta$ receptor type-1 (TGF $\beta R 1$ ), 5' -ATTGCT GGACCAGTGTGCTT-3' (forward), 5'-AAACCTGAG CCAGAACCTGA-3' (reverse); TGF $\beta$ receptor type-2 (TGFßR2), 5' -AGTCGGATGTGGAAATGGAG-3' (forward), 5'-GCTCATGCAGGATTTCTGGT-3' (reverse). QPCR reactions were normalized by amplifying the same cDNA with GAPDH primers, 5'-ACAGTCAGCC GCATCTTCTT-3' (forward), 5' -ACGACCAAATCCGT TGACTC-3' (reverse).

QPCR was performed using Platinum SYBR Green qPCR SuperMix-UDG (Invitrogen). Amplification and detection were carried out using Mx3000P System (Stratagene). The PCR cycling program consisted of 40 threestep cycles of $15 \mathrm{~s} / 95{ }^{\circ} \mathrm{C}, 30 \mathrm{~s} / \mathrm{T}_{\mathrm{A}}$, and $30 \mathrm{~s} / 72{ }^{\circ} \mathrm{C}$. Each sample was amplified in duplicate. In order to confirm signal specificity, a melting program was carried out after the PCR cycles were completed. The samples were quantified by comparison with a standard calibration curve created at the same time and the data was normalized by an internal control (GAPDH).

\section{Western blot analysis}

Whole cell protein lysates were generated using RIPA Lysis Buffer (Millipore), containing a protease inhibitor cocktail (Roche). Protein concentrations were determined using the BCA Protein Assay Kit (Pierce). A total of $10-50 \mu \mathrm{g}$ of whole cell lysates were denatured, reduced, and resolved on SDS-polyacrylamide gels by SDS-PAGE before transfer onto $0.45 \mu \mathrm{m}$ pore size Immobilon-P polyvinylidene fluoride (PVDF) membranes (Millipore).

Membranes were incubated with blocking buffer (TBS, $0.25 \%$ Tween-20, $0.1 \%$ serum from species that secondary antibody was raised in, and $10 \%$ fat-free skimmed milk) for $1 \mathrm{~h}$ at room temperature. Membranes were subsequently probed overnight with either anti-NPRA (FabGennix Inc. International), anti-ASMA (Sigma), anti-phospho Smad2 (Cell Signaling Technologies), antitotal Smad2 (Cell Signaling Technologies), or antiphospho ERK (Cell Signaling Technologies). Detection of the specific binding of the primary antibody was achieved using HRP-conjugated secondary antibodies, followed by signal detection with Immobilon Western chemiluminescent HRP substrate (Millipore) according to the manufacturer's instructions. Anti-beta tubulin (Sigma) was used to verify equal loading.

\section{Immunoassay}

Both total and active forms of TGF $\beta 1$ released by HCF were quantified in cell supernatants. An acid activation step was carried out for assessment of total TGF $\beta 1$. This involved incubating the sample in $1 \mathrm{~N} \mathrm{HCl}$ for $10 \mathrm{~min}$ at 
room temperature, followed by neutralization with $1.2 \mathrm{~N}$ $\mathrm{NaOH} / 0.5 \mathrm{M}$ Hepes. This step was excluded when assaying for active TGF $\beta 1$ within the cell culture supernatant. Following sample preparation, TGF $\beta 1$ was quantified using the human active TGF $\beta 1$ ultra-sensitive immunoassay with electrochemiluminescence detection as instructed by the manufacturer (Meso Scale Discovery). This assay exhibits a large dynamic range suitable for quantifying $\mathrm{pg} / \mathrm{mL}$ concentrations in the supernatants of the cultured cardiac fibroblasts.

\section{Immunofluorescence microscopy}

HCF cells adhered to BioFlex wells were fixed in $4 \%$ paraformaldhyde for 20 min prior to being immuno-stained with either anti-NPRA (1:25) or immunoglobulin control at the same protein concentration, for $1 \mathrm{~h}$ at room temperature. Fluorescent detection of NPRA was achieved using Alexa Fluor 568 conjugated secondary antibody (Invitrogen), followed by nuclear staining with 4'-6-diamidino-2-phenylindole (DAPI). The silicone wells containing the immuno-stained cells were subsequently excised, mounted onto microscope slides, and visualized using fluorescent microscopy (Zeiss Axio Imager M1). Images were acquired at the same exposure time for comparison.

\section{Statistical analysis}

Comparisons between the control and stretched groups were made using independent $t$-test or ANOVA (Tukey post-hoc analysis), where appropriate, with $P$ values $\leq 0.05$ considered statistically significant. All statistical calculations were performed using Graph Pad prism Software (Version 4, San Diego, CA, USA).

\footnotetext{
Abbreviations

ASMA: Alpha-smooth muscle actin; BNP: B-type natriuretic peptide; ERK: Extracellular-signal-regulated kinases; HCF: Primary human adult cardiac fibroblast cells; NPRA: Natriuretic peptide receptor A; QPCR: Quantitative realtime PCR; TGF $\beta$ : Transforming growth factor beta; TGF $\beta-R$ : Transforming growth factor beta receptor.
}

\section{Competing interests}

The authors declare that they have no competing interests.

\section{Acknowledgements}

The Authors wish to thank Dr Michaela Kuhn (Institute of Physiology, University of Würzburg, Germany) for the kind gift of the pcDNA3_GCA expression construct. The authors would also like to thank the Health Research Board of Ireland (grant number RP/2007/313 to JB and KM) for supporting this work.

\section{Author details}

${ }^{1}$ School of Medicine \& Medical Science, The Conway Institute of Biomolecular and Biomedical Research, University College Dublin, Dublin, Ireland. 'Heart Failure Unit, St Vincent's University Hospital Healthcare Group, Elm Park, Dublin, Ireland.

\section{Authors' contributions}

CW, DP, MX, PC, and RN carried out the experiments and performed the data analysis. CW, DP, AS, ML, KM, and JB designed the experiments, interpreted the data, and wrote the final manuscript. All authors read and approved the final manuscript.

Received: 1 March 2012 Accepted: 7 July 2012

Published: 7 July 2012

\section{References}

1. Ciulla M, Paliotti R, Hess DB, Tjahja E, Campbell SE, Magrini F, Weber KT: Echocardiographic patterns of myocardial fibrosis in hypertensive patients: endomyocardial biopsy versus ultrasonic tissue characterization. J Am Soc Echocardiogr 1997, 10:657-664.

2. Rossi MA: Pathologic fibrosis and connective tissue matrix in left ventricular hypertrophy due to chronic arterial hypertension in humans. J Hypertens 1998, 16:1031-1041.

3. Querejeta R, Varo N, Lopez B, Larman M, Artinano E, Etayo JC, Martinez Ubago JL, Gutierrez-Stampa M, Emparanza Jl, Gil MJ, Monreal I, Mindan JP, Diez J: Serum carboxy-terminal propeptide of procollagen type I is a marker of myocardial fibrosis in hypertensive heart disease. Circulation 2000, 101:1729-1735.

4. Diez J, Querejeta R, Lopez B, Gonzalez A, Larman M, Martinez Ubago JL: Losartan-dependent regression of myocardial fibrosis is associated with reduction of left ventricular chamber stiffness in hypertensive patients. Circulation 2002, 105:2512-2517.

5. Brilla CG, Funck RC, Rupp H: Lisinopril-mediated regression of myocardial fibrosis in patients with hypertensive heart disease. Circulation 2000, 102:1388-1393.

6. Weber KT, Brilla CG, Janicki JS: Myocardial fibrosis: functional significance and regulatory factors. Cardiovasc Res 1993, 27:341-348.

7. Ciulla MM, Paliotti R, Esposito A, Diez J, Lopez B, Dahlof B, Nicholls MG, Smith RD, Gilles L, Magrini F, Zanchetti A: Different effects of antihypertensive therapies based on losartan or atenolol on ultrasound and biochemical markers of myocardial fibrosis: results of a randomized trial. Circulation 2004, 110:552-557.

8. Brilla CG, Rupp H, Maisch B: Effects of ACE inhibition versus non-ACE inhibitor antihypertensive treatment on myocardial fibrosis in patients with arterial hypertension. Retrospective analysis of 120 patients with left ventricular endomyocardial biopsies. Herz 2003, 28:744-753.

9. van den Borne SW, Diez J, Blankesteijn WM, Verjans J, Hofstra L, Narula J: Myocardial remodeling after infarction: the role of myofibroblasts. Nat Rev Cardiol 2010, 7:30-37.

10. Nishikimi T, Maeda N, Matsuoka $\mathrm{H}$ : The role of natriuretic peptides in cardioprotection. Cardiovasc Res 2006, 69:318-328.

11. Blaauw E, van Nieuwenhoven FA, Willemsen P, Delhaas T, Prinzen FW, Snoeckx LH, van Bilsen M, van der Vusse GJ: Stretch-induced hypertrophy of isolated adult rabbit cardiomyocytes. Am J Physiol Heart Circ Physiol 2010, 299:H780-H787.

12. Christoffersen TE, Aplin M, Strom CC, Sheikh SP, Skott O, Busk PK, Haunso S, Nielsen LB: Increased natriuretic peptide receptor $A$ and $C$ gene expression in rats with pressure-overload cardiac hypertrophy. Am J Physiol Heart Circ Physiol 2006, 290:H1635-H1641.

13. Kapoun AM, Liang F, O'Young G, Damm DL, Quon D, White RT, Munson K, Lam A, Schreiner GF, Protter AA: B-type natriuretic peptide exerts broad functional opposition to transforming growth factor-beta in primary human cardiac fibroblasts: fibrosis, myofibroblast conversion, proliferation, and inflammation. Circ Res 2004, 94:453-461.

14. Nishikimi T, Inaba-lemura C, Ishimura K, Tadokoro K, Koshikawa S, Ishikawa K, Akimoto K, Hattori Y, Kasai K, Minamino N, Maeda N, Matsuoka H: Natriuretic peptide/natriuretic peptide receptor-A (NPR-A) system has inhibitory effects in renal fibrosis in mice. Regul Pept 2009, 154:44-53.

15. Lijnen $P$, Petrov $V$ : Transforming growth factor-beta 1 -induced collagen production in cultures of cardiac fibroblasts is the result of the appearance of myofibroblasts. Methods Find Exp Clin Pharmacol 2002, 24:333-344.

16. Lijnen PJ, Petrov W, Fagard RH: Induction of cardiac fibrosis by transforming growth factor-beta(1). Mol Genet Metab 2000, 71:418-435.

17. Bujak M, Frangogiannis NG: The role of TGF-beta signaling in myocardial infarction and cardiac remodeling. Cardiovasc Res 2007, 74:184-195.

18. Vaughan MB, Howard EW, Tomasek JJ: Transforming growth factor-beta1 promotes the morphological and functional differentiation of the myofibroblast. Exp Cell Res 2000, 257:180-189. 
19. Merryman WD, Lukoff HD, Long RA, Engelmayr GC Jr, Hopkins RA, Sacks MS: Synergistic effects of cyclic tension and transforming growth factorbeta1 on the aortic valve myofibroblast. Cardiovasc Pathol 2007, 16:268-276.

20. Sadoshima J, Jahn L, Takahashi T, Kulik TJ, Izumo S: Molecular characterization of the stretch-induced adaptation of cultured cardiac cells. An in vitro model of load-induced cardiac hypertrophy. J Biol Chem 1992, 267:10551-10560.

21. Tomasek JJ, Gabbiani G, Hinz B, Chaponnier C, Brown RA: Myofibroblasts and mechano-regulation of connective tissue remodelling. Nat Rev Mol Cell Biol 2002, 3:349-363.

22. Blaauboer ME, Smit TH, Hanemaaijer R, Stoop R, Everts V: Cyclic mechanical stretch reduces myofibroblast differentiation of primary lung fibroblasts. BiochemBiophys Res Commun 2011, 404:23-27.

23. Westermann D, Lindner D, Kasner M, Zietsch C, Savvatis K, Escher F, von Schlippenbach J, Skurk C, Steendijk P, Riad A, Poller W, Schultheiss HP, Tschope C: Cardiac inflammation contributes to changes in the extracellular matrix in patients with heart failure and normal ejection fraction. Circ Heart Fail 2011, 4:44-52.

24. Kuwahara F, Kai H, Tokuda K, Takeya M, Takeshita A, Egashira K, Imaizumi T: Hypertensive myocardial fibrosis and diastolic dysfunction: another model of inflammation? Hypertension 2004, 43:739-745.

25. Takahashi N, Calderone A, Izzo NJ Jr, Maki TM, Marsh JD, Colucci WS: Hypertrophic stimuli induce transforming growth factor-beta 1 expression in rat ventricular myocytes. J Clin Invest 1994, 94:1470-1476.

26. Shiota N, Rysa J, Kovanen PT, Ruskoaho H, Kokkonen JO, Lindstedt KA: A role for cardiac mast cells in the pathogenesis of hypertensive heart disease. J Hypertens 2003, 21:1935-1944.

27. Syedain ZH, Tranquillo RT: TGF-beta1 diminishes collagen production during long-term cyclic stretching of engineered connective tissue: implication of decreased ERK signaling. J Biomech 2011, 44:848-855.

28. Tsuruda T, Boerrigter G, Huntley BK, Noser JA, Cataliotti A, CostelloBoerrigter LC, Chen HH, Burnett JC Jr: Brain natriuretic Peptide is produced in cardiac fibroblasts and induces matrix metalloproteinases. Circ Res 2002, 91:1127-1134.

29. Huntley BK, Sandberg SM, Noser JA, Cataliotti A, Redfield MM, Matsuda Y, Burnett JC Jr: BNP-induced activation of CGMP in human cardiac fibroblasts: interactions with fibronectin and natriuretic peptide receptors. J Cell Physiol 2006, 209:943-949.

30. Jarvis MD, Rademaker MT, Ellmers LJ, Currie MJ, McKenzie JL, Palmer BR, Frampton CM, Richards AM, Cameron VA: Comparison of infarct-derived and control ovine cardiac myofibroblasts in culture: response to cytokines and natriuretic peptide receptor expression profiles. Am J Physiol Heart Circ Physiol 2006, 291:H1952-H1958.

31. Koivisto E, Karkkola L, Majalahti T, Aro J, Tokola H, Kerkela R, Ruskoaho H: MCAT element mediates mechanical stretch-activated transcription of Btype natriuretic peptide via ERK activation. Can J Physiol Pharmacol 2011, 89:539-550

32. Gan Q, Yoshida T, Li J, Owens GK: Smooth muscle cells and myofibroblasts use distinct transcriptional mechanisms for smooth muscle alpha-actin expression. Circ Res 2007, 101:883-892.

33. Gabbiani G: The myofibroblast in wound healing and fibrocontractive diseases. J Pathol 2003, 200:500-503.

34. Dalla Costa AP, Clemente CF, Carvalho HF, Carvalheira JB, Nadruz W Jr, Franchini KG: FAK mediates the activation of cardiac fibroblasts induced by mechanical stress through regulation of the mTOR complex. Cardiovasc Res 2010, 86:421-431.

35. Atance J, Yost MJ, Carver W: Influence of the extracellular matrix on the regulation of cardiac fibroblast behavior by mechanical stretch. J Cell Physiol 2004, 200:377-386.

36. Huntley BK, IChiki T, Sangaralingham SJ, Chen HH, Burnett JC Jr: B-type natriuretic peptide and extracellular matrix protein interactions in human cardiac fibroblasts. J Cell Physiol 2010, 225:251-255.

doi:10.1186/1755-1536-5-9

Cite this article as: Watson et al:: Mechanical stretch up-regulates the Btype natriuretic peptide system in human cardiac fibroblasts: a possible defense against transforming growth factor- $\beta$ mediated fibrosis. Fibrogenesis \& Tissue Repair 2012 5:9.

\section{Submit your next manuscript to BioMed Central and take full advantage of:}

- Convenient online submission

- Thorough peer review

- No space constraints or color figure charges

- Immediate publication on acceptance

- Inclusion in PubMed, CAS, Scopus and Google Scholar

- Research which is freely available for redistribution 